\title{
The Film in Language Teaching Association (FILTA): a multilingual community of practice
}

\author{
Carmen Herrero
}

\begin{abstract}
This article presents the Film in Language Teaching Association (FILTA) project, a community of practice ( $\mathrm{CoP}$ ) whose main goals are first to engage language teachers in practical uses of film and audio-visual media in the second language classroom; second, to value the artistic features of cinema; and third, to encourage a dialogue between language teachers in order to share activities and creative approaches to the use of film and audio-visual texts in language teaching. This article examines the origin, development, experiences, and practices of the international and multilingual community of language teachers that forms FILTA (a community which includes teachers of Arabic, English, French, German, Italian, Mandarin, Spanish, and Urdu). It also looks at some recent European audio-visual and education policies that permeate current trends of film literacy in language teaching, and considers future challenges, including how to maintain growth and further promote engagement within this diverse CoP.
\end{abstract}

\section{Introduction}

Communities of practice (CoPs) 'are groups of people who share a concern, a set of problems, or a passion about a topic, and who deepen their knowledge and expertise in this area by interacting on an ongoing basis' (Wenger, McDermott, and Snyder 2002: 4). In a CoP, members are brought together by joining in common activities and by learning from each other during these activities (Wenger 1998). Indeed, the notion of a 'community of practice' is a key term in Situated Learning, a theory that implies that learning is a social process, which takes place by solving problems with the support of other learners (Lave and Wenger 1991).

CoPs have become an integral part of the structure of many organizations, and their model of social learning has also been applied to the work of professional practice in education, including language education (Nishino 2012). This article presents Film in Language Teaching Association (FILTA) ${ }^{1}$, a language association that was designed to function as a CoP. 
Wenger et al. (ibid.) have distinguished five stages in the development of a CoP:

1 potential

2 coalescing

3 maturing

4 stewardship

5 transformation.

The first four of these phases will guide this analysis of the Association, examining the origin, development, experiences, and practices of the international and multilingual community of language teachers from a range of backgrounds that comprise FILTA. As this project has not yet reached the $5^{\text {th }}$ stage of the development of a CoP, the final part of this article will consider future challenges, including how to maintain growth, and further promote engagement within this diverse CoP.

\section{Potential: a decade of collaboration in the UK}

Different projects, organizations, and challenges have helped to lay the foundations of FILTA (based originally in the north-west of England). One of the most important and successful of these activities, testing the use of film for language teaching in the UK, has been Modern Foreign Languages Study Days, an educational programme delivered in collaboration with and hosted at Cornerhouse, a multidisciplinary arts centre in Manchester, which later changed its name to HOME (see Appendix). Running since 1999 and aimed at 14-17-year-old school students, these events include a full screening of a feature film, an introduction to the film, and activities and discussions closely tied to the students' language curriculum. Pupils receive a comprehensive resource pack to be used during and after the event. In fact, it is the study guides for French, Spanish, and Latin American films that have played a central role in the popularity of these events.

Early feedback from these sessions included requests to provide teacher training 
sessions to guide TESOL/TEFL and modern language teachers, particularly those with no experience of teaching film. This demand gradually increased as the current UK secondary school leaving qualification (A Levels) syllabus for Modern Languages includes the study of specific films and/or film-makers. Thus, the second filmrelated project encompassed the co-organization and delivery of workshops and INSET, and the launch of the module Film Pedagogy, which is part of the MA TEFL at Manchester Metropolitan University. All these events proved to be successful in attracting teachers from across different languages and levels interested in innovative pedagogical approaches in this field.

Indeed, the potential for establishing a $\mathrm{CoP}$ in the field of film and moving image applied to language learning and teaching is linked to the increasing importance of a wider range of literacies, including multimodal literacy and media literacy, which 'necessarily involves "reading" and "writing" media' (Buckingham 2003: 4). Furthermore, UNESCO and the European Union (British Film Institute 2015) have identified media education, linked to digital literacy, as a priority for the twenty-first century. In fact, numerous studies have found evidence of the direct positive effect of media and film literacies on the print literacy of children and young learners, and on the motivation and engagement in literacy of both students and teachers (Bazalgette 2009; Brooks, Cooper, and Penke 2012). Learning from empirical evidence built through the long-term mutual collaboration with Cornerhouse noted above, FILTA founders have argued that similar positive impacts are applicable to the use of film for language learning and teaching. Overall, research over the last 15 years into the impact of multimodal audio-visual texts on language learning has identified positive benefits. For example, short films and films can help to:

- improve language skills (for example by building vocabulary, increasing attainment in writing, and improving the aural and oral competences);

- foster visual and media literacies;

- nurture critical thinking and creativity;

- promote cultural understanding and communication across cultures; and 
- support lifelong language learning.

In addition to such pedagogical and curricular changes, these film-related projects in north-west England so responded to the national decline in the uptake of languages in British schools and higher education, and particularly to the fact that language study was perceived to be difficult and that apparently uninspiring teaching methods in schools demotivated pupils. At the same time, research indicates that foreign language films can not only increase motivation levels but also enhance intercultural understanding, thus supporting schools with a community cohesion agenda.

After ten years of collaboration, the two partners involved in the Modern Foreign Languages Study Days joined with Routes into Languages North West (see Appendix) and won a joint bid to further extend the programme to Arabic, Italian, Mandarin, and Urdu, which are the most relevant Community and Lesser Taught Languages in the region. (Routes into Languages is a UK national project funded by the Higher Education Funding Council for England. It comprises of nine regional centres with over 80 universities working together and promotes the teaching and learning of all languages including community and lesser-taught languages in both main and supplementary schools and colleges.) This pilot project, part of the British Film Institute's Film: $21^{\text {st }}$ Century Literacy campaign, was designed to introduce film across the curriculum, in this case by promoting the use of film across a wide range of languages taught in 11-18 education. It also aimed to overcome the lower status in the UK of community languages, and the perception found in minority groups that their languages and cultures were not valued in an increasingly multicultural country. Creative workshops for students, integrating ICT and film-making techniques with language learning, were a key component of the project, for example:

- planning their own short film through use of a story board;

- writing the film script/ story;

- creating props/characters and film set (backdrop); 
- identifying the film crew and their responsibilities;

- making a short film using various techniques (for example Stop Motion Animation);

- editing the short film using various tools and software (for example titles, transitions, sound, special effects, etc.).

Furthermore, this project aimed to support audience development by encouraging teachers to bring students to project events and opening students' minds to the idea of independently attending special events at cinemas. Feedback from 70 students from the Manchester region who attended six film study sessions (Arabic, Chinese, Italian, and Urdu) reported that watching the film and studying historical facts in relation to the film were the most enjoyable activities of the day. By the end of the project, the number of pupils who said they were definitely considering studying languages for their A Level (school leaving) qualification increased by one fifth; 94 per cent indicated that the activities had definitely increased their interest in learning languages. Similarly, 94 per cent of respondents affirmed they would like to watch more subtitled films (British Film Institute 2012). To close the project, an INSET for community language teachers took place in February 2010. The toolkit Using Film to Teach Languages (Chan and Herrero 2010) outlines the principles and outcomes of this intervention and the activities carried out during the training day.

\section{Coalescing and maturing: FILTA as an international CoP}

During the second stage of its development, coalescing, the CoP is officially launched. Activities and events are organized to allow members 'to build relationships, trust, and awareness of their common needs' (Wenger et al. op.cit.: 82). In the case of FILTA, the feedback collated from students and teachers assessing the impact of materials and events from 1999-2009 (for example increasing motivation and engagement, pupils achieving a higher grade and, particularly, a rise in uptake of languages in the penultimate year in secondary education) confirmed the potential for a $\mathrm{CoP}$ in the use of film for language teaching. Ultimately, the 
experiences and lessons learnt from these projects contributed to the establishment of FILTA in February 2010. FILTA was officially inaugurated with the launch of the Association website that was created thanks to the sponsorship of Routes into Languages North West and the support of Manchester Metropolitan University.

The basic characteristics of a CoP are: it has a domain of knowledge; it is a community that interacts; and practice - the sharing of experiences, tools, and resources in order to maintain the core of knowledge-is central. These key issues at the coalescing stage will guide the following sections.

\section{A domain of knowledge}

First, it is useful to look at some current European audio-visual and education policies that permeate recent trends of film literacy in language teaching. Appropriate recognition of film education is one of the priorities highlighted in the most recent Creative Europe Programme (a European Union funded programme, see Appendix) in order to support audience development, in particular young audiences. It aims to implement activities aimed at promoting film literacy, which was defined in the initial programme report, Screening Literacy in Europe (British Film Institute 2013), as

the level of understanding of a film, the ability to be conscious and curious in the choice of films; the competence to critically watch a film and to analyse its content, cinematography and technical aspects; and the ability to manipulate its language and technical resources in creative moving image production.

(Emphasis in original.)

This definition encapsulates the '3Cs', the critical, cultural, and creative approaches of film and media literacy, which are the key dimension of the final programme report, the Framework for Film Education (British Film Institute 2015). This latter document looks to consolidate European film education models (theory and practice) and establish the fundamental learning goals for learners to:

understand what is specific and distinctive about film; know that film is both 
collectively and collaboratively, as well as personally and individually, produced and consumed; personally engage with film from a critical, aesthetic, emotional, cultural and creative perspective; regularly access a wide variety of film and film form; develop an awareness of the social and historical context to film; be able to reflect upon the different ways of experiencing, exploring, and learning about film. (ibid.: 3)

Second, in another report For a European Film Education Policy, Lardoux (2014: 44) advocates the 'large-scale development of film education activities combining artistic and linguistic approaches'. This is particularly interesting because this is precisely FILTA's domain of knowledge: the teaching and learning of foreign languages through film and audio-visual media, therefore promoting both language learning and the key dimensions of film education (the critical, the cultural, and the creative) as interwoven strands. FILTA supports the '3Cs' approach and advocates the significant cognitive and affective benefits that the use of the moving image has and the positive impact that this could provide to teachers' pedagogy and students' learning activities and projects, particularly, as it could bring a global, multilingual, and intercultural dimension to language learning. With this guiding common ground, FILTA promotes this domain of knowledge by providing information and publications, creating a flexible online-learning environment that incorporates an expanding collection of materials, and co-organizing professional development activities. $^{2}$

\section{A community: fostering interactions}

In his research on subject associations, Lamb (2012: 290) provides a useful insight into the key functions and challenges they face 'in shifting times'. Among the challenges faced by many language teacher associations around the world is that of falling membership and, consequently, fewer services and lower visibility. Lamb's research points out the need to attract younger teachers by promoting 'a more modern image and appeal' (ibid.: 298). As Don Tapscott has noted, the twenty-first century is the 'age of collaboration' and many language teachers are not only promoting that principle in their classes, but are also engaging in collaborative 
activities for their own professional growth. Social networking allows teachers to connect in order to develop professional learning, to share thoughts and projects, and to develop their Personal Learning Environments. For all these reasons, working with the theoretical framework of 'learning in a participatory culture' (Jenkins, Purushotma, Weigel, Clinton, and Robison 2009), FILTA was conceived as an online professional learning community, which would encourage the use of collaboration to solve problems, and the use of technology to shape the flow of media. An important stage when planning FILTA's characteristics was deliberating on the design features of the association in order to create a strong and rich CoP that could foster interactions between teachers of different languages and countries, and encourage and facilitate sharing ideas and resources. For this reason, FILTA was designed with the idea of creating a sustainable model of association, rich in open resources, and without a membership fee. Considering the intended international scope of the association, this was quite an ambitious and exciting goal. This project was also a practical way of inspiring language educators to use the tools provided by Web 2.0 technologies, join in a new participatory culture and encourage them to promote the digital, cultural, and social skills that their students would need in their future roles as twenty-first century citizens and workers (Herrero and Valbuena 2011). Thus, FILTA has developed a website with the Association mission statement. It also provides a summary of the aims in Arabic, French, German, Italian, Mandarin, Spanish, and Urdu. The site allows visitors to request a free membership and, once they are members, to get access to the social space of the Association, 'filtacommunity' (http://filtacommunity.ning.com).

Web 2.0 technologies are promoting collaboration between network users as they make it easier to share information, opinions, and data with peers of a community. The FILTA 'ning' space provides a fully functional platform, which includes a blog feature and a forum, as well as Twitter, Facebook, and other online social networking services. A popular social platform among educators, the Ning social networking tool was selected for the social space it provides for users and its rich range of easy-to-use multimedia resources for interaction (www.ning.com). Members have a great level of freedom regarding the content and look of their 
personal page on the site as they can customize their profile (for example photo, RSS feeds, and widgets). Individual members can add friends to their circle, and they are also able to directly invite other colleagues who could be interested in joining the Association. This is a key practice during the maturing stage. Currently there are 2,648 registered members from 90 countries, with an average increase of 500 members per year, and it is noteworthy that 50 per cent of the membership has been achieved via peer-to-peer invitation. As Table 1 shows, members from the UK represent more than 50 per cent of the total, and are more active in terms of their engagement with the filtacommunity. Members are able to renounce membership by themselves although over five years only 17 people have left the Association. FILTA is mainly an association of language teachers; but, in order to enrich the value of this community, it is open to the development of reciprocal links with other language associations and encourages media education organizations and practitioners of the media industries to become active members of the Association (for example British Film Institute).

\begin{tabular}{|l|l|l|}
\hline Country & $\begin{array}{l}\text { Number of sessions } \\
\text { (Total: 17,003) }\end{array}$ & Percentage of sessions \\
\hline 1 United Kingdom & 11,005 & 64.72 \\
\hline 2 Spain & 1,930 & 11.35 \\
\hline 3 United States & 966 & 5.68 \\
\hline 4 Ireland & 791 & 4.65 \\
\hline 5 France & 347 & 2.04 \\
\hline 6 Argentina & 196 & 1.15 \\
\hline 7 Italy & 141 & 0.83 \\
\hline 8 Germany & 137 & 0.81 \\
\hline
\end{tabular}




\begin{tabular}{|l|l|l|}
\hline 9 (not set) & 128 & 0.75 \\
\hline 10 Brazil & 114 & 0.67 \\
\hline
\end{tabular}

Table 1 The number of sessions and countries for filtacommunity (2010-2015) based on the Google analytics report ${ }^{3}$

\section{Practices}

The filtacommunity platform includes a series of features that encourage sharing experimentation, innovation, and models of good practice. It allows members to set up individual blogs and contribute to the FILTA blog and participate in forum discussions. Examples of these include requesting information on a specific film, sharing resources, or suggesting potential film or short films to use in the language classroom. FILTA members can share information related to their activity on the filtacommunity via Facebook and Twitter; and they can connect with other members via synchronous chat. Another important design feature that allows users to have greater autonomy is that they are able to upload photos and videos (trailers, teasers, short films from Vimeo or YouTube, for example), which have potential use in the language classroom; or add information about an event related to the fields of interest of the community (see Figure 1). Examples of these include:

- workshops for students (for example French/German/Spanish Essay Writing for Film);

- film languages study days;

- INSET (for example Using Film in the MFL Classroom);

- multimodal approaches for the use of film and moving image media;

- visual literacy (i.e. using short films in the language classroom);

- creative subtitling; 
- symposia and conferences (for example music and cognition in language learning);

- film festivals; and

- online chats (How to Use Film Creatively in Class Teaching: Tips and Ideas).

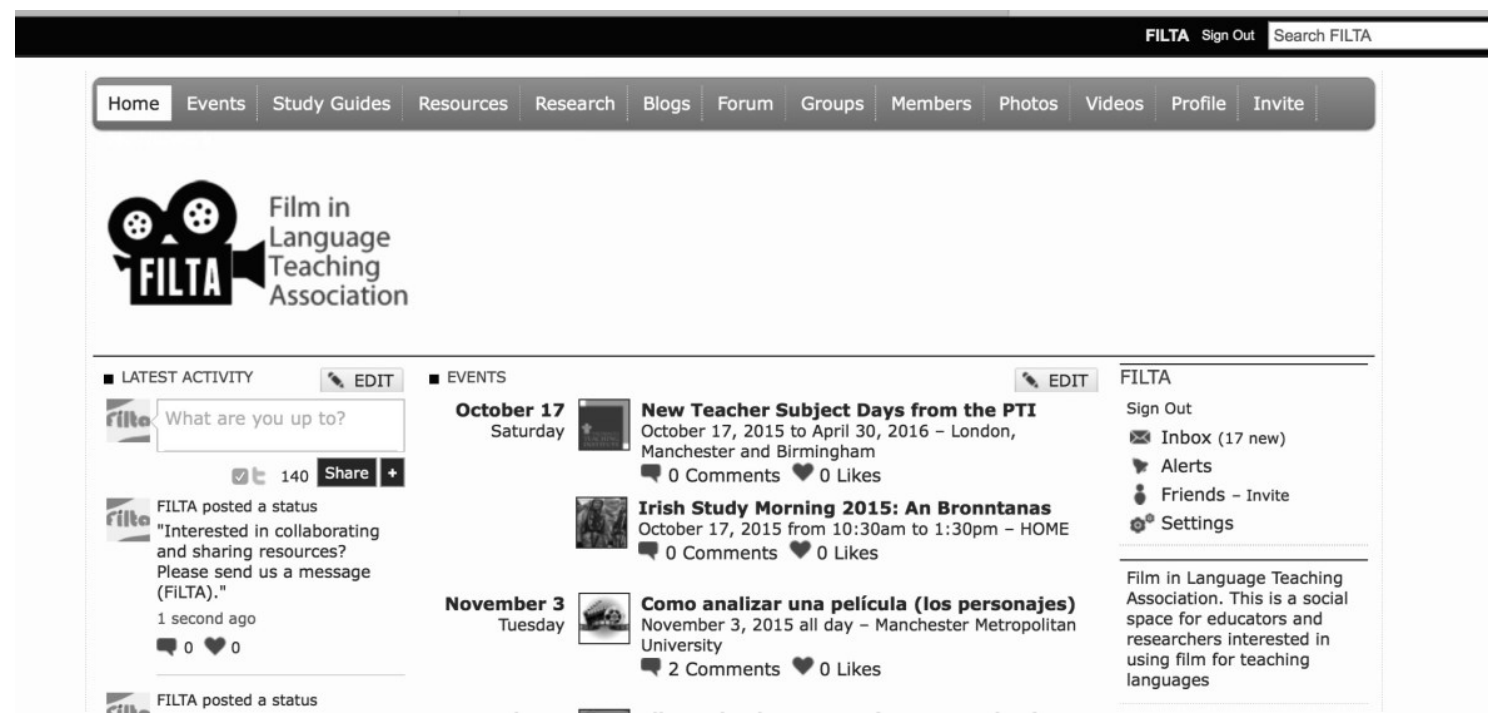

Figure 1 Screenshot of the filtacommunity home page

Another way of conceptualizing FILTA is as a 'constellation of practices' (Wenger op.cit.). As members of FILTA are from different and sometimes overlapping CoPs in and outside the filtacommunity, it provides a social environment for subgroups to develop further exchanges about specific issues. Currently it hosts a number of groups related to languages: Arabic, English (TEFL), Estudios Latinoamericanos, French, German, Italian, Mandarin, Spanish, and Urdu. It also hosts cross-curricular groups such as Digital Storytelling, Film for Children and Young Audiences, Film Literary Adaptations, GCSE Learning, Subtitling and Revoicing in L2. Multilingual communication is encouraged through the site and it is particularly relevant in the language groups.

The most popular area of the community site holds study guides for each of the languages, with the Spanish area being the most visited. Most of the study guides are based on feature films, and are designed to aid language learners in analysing a 
specific film. The activities help students to develop critical thinking skills (predict, infer, ask questions) and creative media competences. Other benefits include opportunities to establish connections across curriculum areas and reflect on cultural experiences, thereby improving students' intercultural competence..

The members can share their own materials via the specific groups, the blog, and/or the forum areas. There is an area dedicated to sharing research resources in the subject area.

\section{Stewardship}

Moving from the 'potential', through 'coalescing' of goals and objectives and 'maturing' as a community, FILTA is now in the 'stewardship' stage. The main issues at this point are 'to maintain the relevance of the domain and to find a voice in the organization' (Wenger et al. op.cit.: 104); and, of course, to sustain the momentum of the CoP by expanding collaborations, and encouraging members to participate in a more active way, as well as developing the current and new subgroups There is now an even greater opportunity to grow and share the knowledge that it has accumulated. Strategically, FILTA is planning to introduce online events, such as free webinars that could support and strengthen the links across different countries and languages. We aim to diversify the profile of our membership by expanding the language groups, recruiting teacher trainees and establishing links with other networks (such as the research group Film, Languages And Media in Education or FLAME, see Appendix) in order to raise the profile of FILTA nationally and internationally. We have identified the English language group as the one with higher potential for growth and would encourage interested EFL/ESOL teachers and trainers to cooperate with FILTA in the organization of activities, and provide knowledge and resources within the domain of our CoP. Analysing the online activities among members of FILTA is helping to uncover patterns of interaction, and activities within groups and individual members (the social structures through which knowledge is generated and spread through the community). For example, we have recently observed how teachers tend to join two or more different groups; and how the area dedicated to videos is one of the most visited. Finally, FILTA is 
currently exploring new avenues that will sustain its growth, such as securing financial support via sponsorship.

\section{Conclusion}

Film texts are perfect vehicles for introducing students to different types of popular culture and engaging them with critical questions about the relationship between information and power, through the critical analysis of socio-political issues and intercultural relationships. While video, film, and audio-visual media and video making are gradually achieving importance as effective tools in foreign language teaching, the challenge for teachers is often to find ways of successfully integrating audio-visual media in the foreign language curriculum. These trends explain the interest, growth, and engagement that FILTA has achieved since it started in 2010. Using the enormous potential of the internet and particularly of social networks, FILTA offers a space where an international language educational community can learn from other colleagues, and share and exchange ideas, experiences, and materials. FILTA has been highly successful in gaining membership internationally; facilitating interdisciplinary links between languages and media; producing quality resources; offering expertise across different languages; and creating and sharing study guides at different levels ready to be used in the classroom with clear links to the common European Framework of Reference for Languages. Through the CoP model, FILTA has given many language teachers and media educators the opportunity to experiment with and experience a rich online social space where they can share a repertoire of resources and practices, thus becoming a useful tool for professional development. As for the future, we hope that FILTA will be able to keep growing while widening its boundaries. The challenge is to avoid diluting the focus which could take FILTA to the last stage of a CoP, the 'radical transformation' or death of the community (Wenger et al. op.cit.: 109). FILTA intends to explore effective ways to sustain its work in the future, connecting language teachers, researchers, and media practitioners via online interactions as well as face-to-face events; and encouraging mentoring across different languages and groups to further develop shared practices and teaching materials. 
Final version sent December 2015

\section{Notes}

1 A full list of websites cited is included in the Appendix.

2 Further details on the FILTA mission statement can be found on the website (www.filta.org.uk).

3 'A session is a group of interactions that take place on your website within a given time frame. For example a single session can contain multiple screen or page views, events, social interactions and ecommerce transactions' (https://support.google.com/analytics/answer/2731565?hl=en).

\section{References}

Bazalgette, C. 2009. Impacts of Moving Image Education: A Summary of Research. Glasgow: Scottish Screen.

British Film Institute. 2012. 21 ${ }^{\text {st }}$ Century Literacy Pilot Project Blueprints. London: British Film Institute. Available at http://www.bfi.org.uk/about-bfi/policy-strategy/consultationspublications/publications-archive\#21st-century-literacy (accessed on 20 March 2015).

British Film Institute. 2013. Screening Literacy in Europe. London: British Film Institute. Available at http://www.bfi.org.uk/screening-literacy-film-education-europe (accessed on 20 March 2015).

British Film Institute. 2015. A Framework for Film Education. Available at http://www.bfi.org.uk/sites/bfi.org.uk/files/downloads/\%20bfi-a-framework-for-filmeducation-brochure-2015-06-12.pdf (accessed on 30 September 2015).

Brooks, R., A. Cooper, and L. Penke. 2012. Film: 21st Century Literacy. Teaching Using Film - Statistical Evidence. London: 21st Century Literacy. Available at http://www.bfi.org.uk/sites/bfi.org.uk/files/downloads/film-21st-century-literacy-teachingusing-film-statistical-evidence.pdf (accessed on 20 March 2015).

Buckingham, D. 2003. Media Education: Literacy, Learning and Contemporary Culture. Cambridge: Polity Press. 
Chan, D. and C. Herrero. 2010. Using Film to Teach Languages. Manchester: Routes into Languages, Film: 21st Century Literacy, the UK Film Council, and Cornerhouse. Available at http://www.cornerhouse.org/wpcontent/uploads/old_site/media/Learn/General\%20docs/TeachersToolkit_Jun2010.pdf (accessed on 20 March 2015).

Herrero, C. and A. Valbuena. 2011. 'Cultura participativa y alfabetización multimodal aplicadas a la enseñanza de lenguas' in M. Buisine-Soubeyroux and J. Seguin (eds.). Image et Education. Lyon: Le Grihm and Université Lumiere-Lyon 2.

Jenkins, H., R. Purushotma, M. Weigel, K. Clinton, and A. J. Robison. 2009. Confronting the Challenges of Participatory Culture: Media Education for the $21^{\text {st }}$ Century. Cambridge, MA: MIT Press. Available at https://mitpress.mit.edu/sites/default/files/titles/free_download/9780262513623_ Confronting_the_Challenges.pdf (accessed on 20 March 2015).

Lamb, T. E. 2012. 'Language associations and collaborative support: language teacher associations as empowering spaces for professional networks'. Innovation in Language Learning and Teaching 6/3: 287-308.

Lardoux, X. 2014. For a European Film Education Policy. Available at http://www.europacreativamedia.cat/rcs media/For a European Film Education P olicy.pdf (accessed on 15 May 2015).

Lave, J. and E. Wenger. 1991. Situated Learning: Legitimate Peripheral Participation. Cambridge: Cambridge University Press.

Nishino, T. 2012. 'Multi-membership in communities of practice: an EFL teacher's professional development'. Teaching English as a Second or Foreign Language 16/2: $1-21$.

Wenger, E. 1998. Communities of Practice: Learning, Meaning, and Identity. Cambridge: Cambridge University Press.

Wenger, E., R. McDermott, and W. Snyder. 2002. Cultivating Communities of Practice. Boston, MA: Harvard University Business School Press.

\section{The author}

Dr Carmen Herrero is a Principal Lecturer in Hispanic Studies at the Manchester 
Metropolitan University. Her research interests are film pedagogy in the language

classroom, new technologies and language teaching, and Hispanic cinemas. She is the cofounder and co-director of FILTA (Film in Language Teaching Association / http://www.filta.org.uk ) and the co-director of the Research group FLAME (Film, Languages And Media in Education / http://www.hssr.mmu.ac.uk/flameresearch/)

Email: c.herrero@mmu.ac.uk

\section{Appendix}

List of website addresses

Cornerhouse/HOME http://homemcr.org

Creative Europe Programme (2014-2020) http://eur-lex.europa.eu/legalcontent/EN/TXT/HTML/?uri=CELEX:32013R1295\&from=ES

FILTA http://www.filta.org.uk/

FLAME https://www.hssr.mmu.ac.uk/flameresearch/

Routes into Languages https://www.routesintolanguages.ac.uk/ 